\title{
Los museos son más oscuros de lo que parece
}

\author{
Antonio Bellido Blanco | Servicio de Museos, Junta de Castilla y León \\ URL de la contribución <www.iaph.es/revistaph/index.php/revistaph/article/view/5032>
}

El turismo oscuro está definido por incidir de forma precisa en la emoción y en la percepción de experiencias negativas. Nuestra historia está llena de personajes malvados y crueles y de espacios "malditos", con lo que en los últimos años no es inusual que se realicen visitas a cementerios, campos de exterminio, cárceles o manicomios; todos ellos lugares donde se ha producido un gran dolor. Llevado al ámbito de los museos parecería que hay que contemplar sólo lo que atañe a determinados museos de sitio y centros de interpretación de enclaves concretos, pero nada hay más alejado de la realidad.

No abundan en España "museos de la vergüenza", de aquellos que pretenden incitar a la reflexión y obligar a considerar los pasos en falso y los errores de los pueblos. Sin embargo, los museos son en general lugares de la memoria cargados de objetos de todo tipo sobre los que pesan multitud de sensaciones negativas. El problema es que los técnicos, los directores, los instaladores y los museólogos han optado de forma generalizada por mostrar una cara amable, quizás en su afán por enseñar deleitando y por hacer que el visitante se sienta feliz. Como dice Šola, es más cómodo crear conocimiento dentro de una categoría científica, basándose en supuestos métodos "objetivos", que desde la conciencia (Šola 2012, 135). No obstante, si quisiéramos cambiar el enfoque de los museos podríamos apreciar que están llenos de testimonios de dolor.

Empezando por los tiempos prehistóricos, nos topamos de bruces con la extinción de especies que nos precedieron en nuestro paso sobre la Tierra. El caso más evidente es el de los neandertales, pero hay muchos más. En tiempos más recientes, el estudio de tumbas megalíticas del Neolítico y el Calcolítico depara en ocasiones el descubrimiento de tremendas masacres. Y la llegada de las legiones romanas ( $y$ antes los ejércitos cartagineses) no mejora en absoluto el panorama, sino que lo empeora claramente. Con posterioridad no dejan de llegar más y más pueblos, tropas y bandas a la península ibérica que imponen el terror o su dominio y control a través del combate y el saqueo.

Este rápido repaso a lo que atañe a los museos arqueológicos y de historia no debe hacer que olvidemos los de bellas artes, que no han de salir mejor parados. En ellos brillan, por su calidad, los retratos de reyes de infausto recuerdo y aparecen también los de dictadores y malos gobernantes. Por su parte las escenas mitológicas abundan en violaciones, incestos, robos, engaños, secuestros, asesinatos y antropofagia. Tampoco hay que dejarse confundir por las representaciones de batallas que, antes que de gloria y conquistas, hablan de muertes y dolor; y ello por más que se disfracen de símbolos de resistencia o de identidad -El Guernica es un buen caso de estudio-. Incluso el arte contemporáneo abstracto juega con matices destinados a causar desazón, ansiedad, desasosiego o angustia en el espectador.

Estos mismos museos y otros de temática religiosa llenan sus muros y salas de representaciones de la pasión de Cristo y del martirio de muchos santos, lo que no deja de ser la sublimación del sufrimiento. Desde Valladolid es obligado recordar el discurso de Ricardo de Orueta escrito en 1924 para su recepción en la Real Academia Bellas Artes de San Fernando bajo el título La expresión de dolor en la escultura castellana. Cada vez son menos las personas que entienden estas recreaciones que adornan la fe cristiana, por más que hayamos convivido con ellas durante siglos.

Los museos etnográficos, envueltos en el encanto de lo rural, no hacen sino maquillar la desaparición de modos de vida que tuvieron vigencia sin apenas alteraciones 


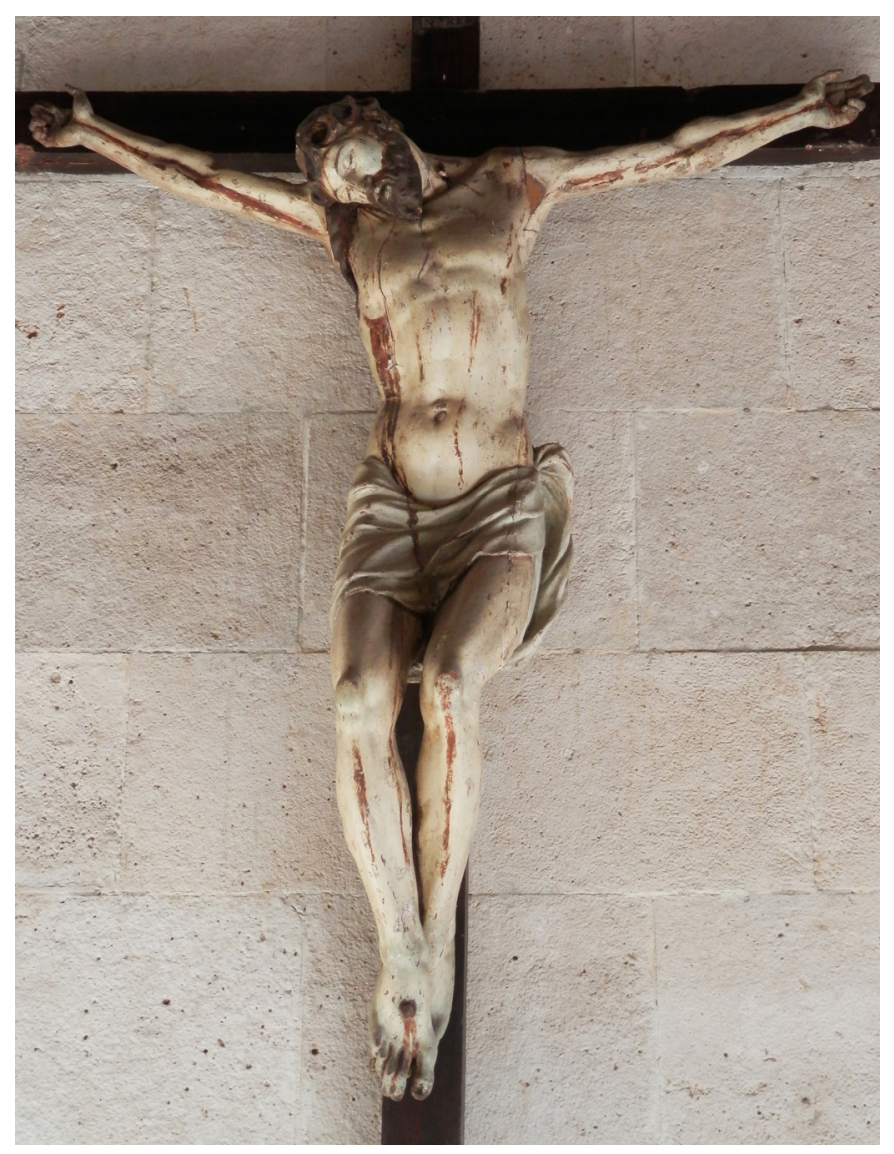

Crucificado en el zaguán de entrada del Museo de Valladolid

desde tiempos inmemoriales y que sustentaban amplios territorios. Hoy muchas comarcas suavizan con reconstrucciones de sus viejas casas la dura realidad actual, en la que han quedado al margen de la organización administrativa abandonados sin posibilidad aparente de recuperación.

Los museos de ciencias naturales presentan de forma frecuente restos óseos, cuerpos disecados o sumergidos en formol de todo tipo de animales y criaturas, incluso humanas, o de partes seccionadas de ellos. Y no profundicemos en museos policiales o del ejército, en los que no faltan objetos con connotaciones siniestras o dramáticas, como armas o prendas de indumentaria asociadas a sucesos concretos. El Museo de la Policía de Ávila dedica una sala al "Crimen", con armas pertenecientes a grupos terroristas, la bomba que explotó en el Liceo de Barcelona en 1893 o el mechón que los secuestradores de Melodie Nakachian enviaron a sus padres en 1987.

¿Y qué hay de la historia de los propios museos, ligada a guerras y expolios? Independientemente de su temática, muchos museos cuentan con piezas conseguidas a través del robo y el engaño, o simplemente por la imposición "legal" de su depósito en instituciones alejadas de los lugares de origen. La Junta de Incautación del Tesoro Artístico es un buen hilo argumental para explicar el esfuerzo por salvar obras fundamentales del patrimonio cultural español durante la Guerra Civil (León 1970).

Ahora que en los países latinoamericanos se reniega tan a menudo del paso de los españoles por allí, ¿recordará alguien en Argentina al padre del general José de San Martín, "prócer nacional de la Argentina y libertador del Perú y Chile"? Pues tiene un pequeño museo en su localidad natal, Cervatos de la Cueza (Palencia), donde se rescata la tradición del siglo XVIII y al tiempo se esfuerzan en mantener su vínculo con Argentina (entre otras cosas, la antigua iglesia parroquial, destruida por un incendio en 1934, fue reconstruida en 1966 con estilo colonial gracias a la aportación de fondos de la República Argentina). Una vez más los discursos museológicos se sitúan lejos de toda memoria oscura y de cualquier trauma.

A día de hoy la decisión de recurrir a la interpretación de los elementos patrimoniales reivindicando una memoria histórica que cuestione determinadas concepciones consolidadas, posiblemente no sólo sea fruto de la labor de los técnicos -que también-, sino de la decisión y la voluntad de instancias políticas en torno a determinadas circunstancias históricas. Y para ello es importante partir de la reivindicación de determinadas comunidades implicadas (Arrieta 2016). La destrucción del pueblo de Ribadelago (Zamora) por la rotura de una presa en 1959 y la muerte de más de una cuarta parte de su población no mereció hasta medio siglo más tarde una exposición en el Museo Etnográfico de Castilla y León (2009) y sólo en 2021 parece que va a salir adelante la creación de 


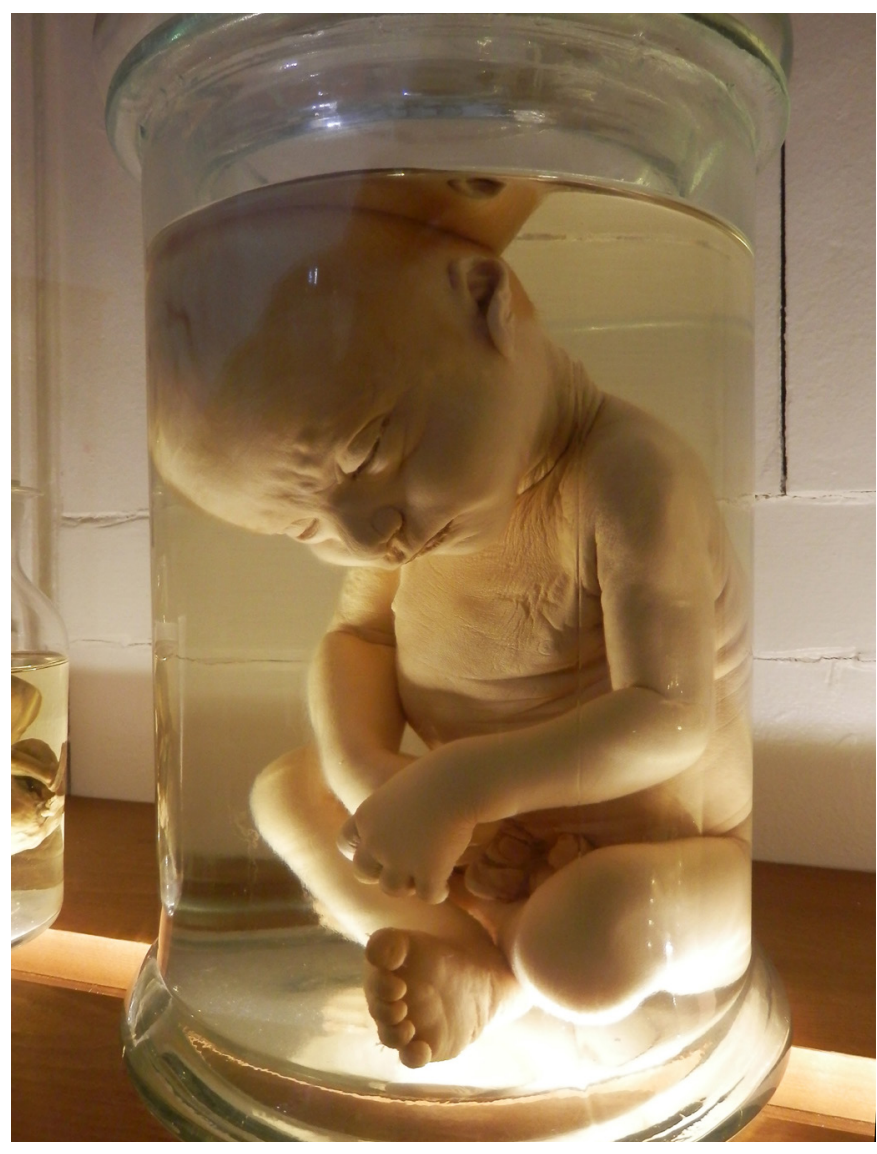

Feto conservado dentro de un tarro en el Museo de Ciencias Naturales (Universidad de Valladolid) | fotos Antonio Bellido Blanco

un museo de la memoria en la localidad, doce años después de que la Junta de Castilla y León se comprometiera a subvencionar la iniciativa.

Ahí está el dolor: en todas partes; pero para verlo hay poder sentirlo y la mediación interpretativa es un aliado esencial si se quiere llegar a los visitantes de los museos.

\section{BIBLIOGRAFÍA}

- Arrieta Urtizberea, I. (ed.) (2016) Lugares de la memoria traumática. Representaciones museográficas de conflictos políticos y armados. Bilbao: Universidad del País Vasco
- León, Ma T. (1970) Memoria de la melancolía. Buenos Aires: Losada

- Museo Etnográfico de Castilla y León (2009) Ribadelago: en el cincuenta aniversario de la rotura de la presa de Vega de Tera y el desastre de Ribadelago de 9 de enero de 1959. Zamora: Museo Etnográfico de Castilla y León. Disponible en: https://museo-etnografico.com/pdf/etno_ribadelago2009.pdf [Consulta: 09/11/2021]

- Šola, T. S. (2012) La eternidad ya no vive aquí. Girona: ICRPC Libres 